\title{
Dependence of Liquid Crystalline Behaviors on Molecular Flexibility
}

\author{
S. A. Maheta, G. N. Bhola, U. C. Bhoya* \\ Department of Chemistry, Saurashtra University, Rajkot - 360005, Gujarat, India \\ EE-mail address: drucbhoya@gmail.com
}

\begin{abstract}
A novel homologous series of thermotropic liquid crystal (LC) has been synthesized with a view to understand and establish the effect of molecular structure on liquid crystal behaviors of a series. The present LC series consist of twelve homologues $\left(\mathrm{C}_{1}\right.$ to $\left.\mathrm{C}_{16}\right)$; whose mesomorphic properties commence from octyloxy $\left(\mathrm{C}_{8}\right)$ homologue of a series. $\mathrm{C}_{8}, \mathrm{C}_{10}$ and $\mathrm{C}_{12}$ members of a series are monotropic smectic and $\mathrm{C}_{14}, \mathrm{C}_{16}$ members are enantiotropically smectogenic. $\mathrm{C}_{1}$ to $\mathrm{C}_{7}$ homologues are nonmesomorphic. Nematogenic property is totally absent. Transition and melting temperatures are determined by an optical polarizing microscopy equipped with a heating stage. Textures of smectic mesophases are focal conic three or two dimensional networking of the type A or C. Cr-I/Sm and Sm-I or I-Sm transition curves behaved in normal manner. Analytical and spectral data confirms the molecular structures of homologues. Thermal stability of smectogenic mesophase is $100.6{ }^{\circ} \mathrm{C}$ and mesomorphic phase length is very short $\left(12.9{ }^{\circ} \mathrm{C}\right.$ to $\left.15.3{ }^{\circ} \mathrm{C}\right)$. LC properties of a present novel series are compared with the structurally similar homologous series. Present series is partly smectogenic and partly non mesomorphic with poor degree of mesomorphism and middle ordered melting type without exhibition of nematogenic behavior.
\end{abstract}

Keywords: Mesomorphic; Mesomorphs; Smectic; Nematic; Liquid crystals

\section{INTRODUCTION}

Thermotropically or lyotropically active Liquid crystal [1] (LC) materials have attracted scientific and technological community in the benefit of mankind [2 - 5]. Technologists and scientists always need novel LC materials to continue and extend and fulfill their aims and objectives; because research is a dynamic activity and not a static. Therefore the researchers working in different disciplines with different angles have thirst for novel LC substance. Thus, present investigation was planned to synthesized novel substances through homologous series; whose common moiety and varying molecular part can induce LC property. Thus, object is aimed with a view to understand the effect of molecular structure $[6,7,8]$ on LC properties and to establish the relations between molecular structure and LC behaviors. Number of LC substances have been reported [9 - 13] till the date. Present ester LC series consisted of three phenyl rings and two central bridges with n-alkoxy and laterally substituted - $\mathrm{Br}$ group at the third phenyl ring. Results are to be discussed, interpreted in terms of molecular rigidity and flexibility and compared with structurally similar series [14 - 17]. 


\section{EXPERIMENTAL}

\subsection{Synthesis}

n-Alkoxy benzoic acids were prepared from 4-hydroxy benzoic acid, by suitable alkylating agents by modified method of dave and vora [18]. $\alpha$-4-Hydroxy phenyl- $\beta-2$ '-bromo benzoyl ethylene was prepared by usual established method [19] (M.P.-168 ${ }^{\circ} \mathrm{C}$, Yield-72.6\%). 4n-Alkoxy benzoic acids and $\alpha$-4-hydroxy phenyl- $\beta$-2'-bromo benzoyl ethylene were condensed in 1, 3-dicyclohexylcarbodiimide (DCC), 4-dimethylaminopyridine (DMAP) and $\mathrm{CH}_{2} \mathrm{Cl}_{2}$ [20] to obtain $\alpha-4-(4$ '-n-Alkoxybenzoyloxy) benzoyl- $\beta-2$ "-bromophenyl ethylenes. Final products were individually decomposed, filtered, washed, dried and purified till the constant transition temperatures obtained.

The synthetic route to the novel homologous series of ethylene derivatives is under mentioned in scheme-1.

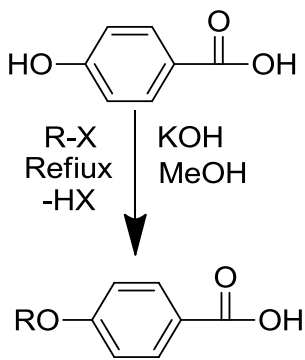

$[\mathrm{A}]$

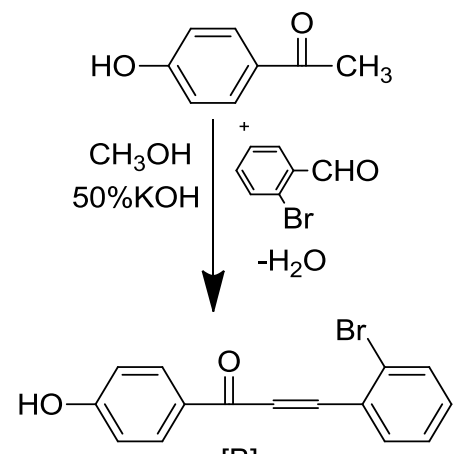

[B]

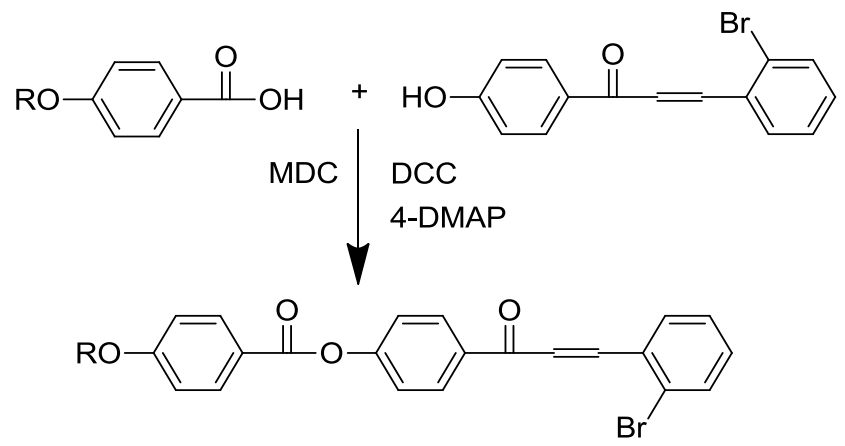

where $\mathrm{R}=\mathrm{C}_{\mathrm{n}} \mathrm{H}_{2 \mathrm{n}+1}, \mathrm{n}=1$ to $8,10,12,14$ and 16

Scheme 1. Synthetic route to the novel series.

\section{CHARACTERIZATION}

Some of members of a novel series as the representative member of a series were characterized by elemental analysis (Table-1), Infrared spectroscopy, ${ }^{1} \mathrm{H}$ NMR spectra and mass spectroscopy. Microanalysis was performed on EuroEA Elemental Analyzer. IR spectra were 
recorded on Shimadzu FTIR Model-IRAffinity-1S (MIRacle 10), ${ }^{1}$ HNMR spectra were recorded on Bruker spectrometer using $\mathrm{CDCl}_{3}$ as a solvent and mass spectra were recorded on Shimadzu GC-MS Model No.QP-2010. The liquid crystal behavior and the type of textures were determined by miscibility method on microscopic observations.

\subsection{Analytical data}

Table 1. Elemental analysis for (1) Ethyloxy (2) Hexyloxy (3) Tetradecyloxy derivatives.

\begin{tabular}{clcccccc}
\hline Sr.No. & $\begin{array}{l}\text { Molecular } \\
\text { formula }\end{array}$ & \multicolumn{3}{c}{ Elements \%Found } & \multicolumn{3}{c}{ Elements \%Calculated } \\
\cline { 3 - 8 } 1 & $\mathrm{C}_{24} \mathrm{H}_{19} \mathrm{BrO}_{4}$ & 63.90 & 4.22 & 14.19 & 63.87 & 4.24 & 14.18 \\
\cline { 3 - 7 } 2 & $\mathrm{C}_{27} \mathrm{H}_{25} \mathrm{BrO}_{4}$ & 65.78 & 5.10 & 12.91 & 65.73 & 5.11 & 12.97 \\
3 & $\mathrm{C}_{36} \mathrm{H}_{43} \mathrm{BrO}_{4}$ & 69.71 & 7.03 & 10.36 & 69.78 & 6.99 & 10.33 \\
\hline
\end{tabular}

\section{Spectral Data}

${ }^{1}$ HNMR in ppm for Hexyloxy Derivative

0.89-0.92 (t, $3 \mathrm{H},-\mathrm{CH}_{3}$ of $-\mathrm{OC}_{6} \mathrm{H}_{13}$ group), 1.28-1.42 (m,6 $\left.6 \mathrm{H}_{3} \mathrm{CH}_{3}-\underline{\mathrm{CH}}_{2}-\underline{\mathrm{CH}}_{2}-\underline{C H}_{2}-\right), 1.75$ $\left(\mathrm{p}, 2 \mathrm{H},-\mathrm{CH}_{2}-\mathrm{CH}_{2}-\mathrm{O}-\right), 4.07\left(\mathrm{t}, 2 \mathrm{H},-\mathrm{CH}_{2}-\mathrm{O}-\right), 7.38 \& 8.15(\mathrm{~d}, 1 \mathrm{H},-\mathrm{CH}=\mathrm{CH}-), 7.53-7.54(\mathrm{~d}, 1 \mathrm{H},-$ $\mathrm{CO}-\mathrm{C} \underline{\mathrm{H}}=\mathrm{CH}-)$, 7.82-7.86 (d,1H, -CO-CH=C $\underline{\mathrm{H}}-$ ), 7.47-8.10 (4H, middle phenyl ring), 7.13-7.82 $(4 \mathrm{H}$, phenyl ring with alkoxy chain). The NMR data are reliable with the molecular structure.

\section{${ }^{1}$ HNMR in ppm for Decyloxy Derivative}

0.88-0.90 (t,3H, $-\mathrm{CH}_{3}$ of $-\mathrm{OC}_{10} \mathrm{H}_{21}$ group), 1.25-1.29 (m,12 $\mathrm{H}_{,} \mathrm{CH}_{3}-\mathrm{CH}_{2}-\mathrm{CH}_{2}-\mathrm{CH}_{2}-\mathrm{CH}_{2}-$ $\left.\underline{\mathrm{CH}_{2}}-\underline{\mathrm{CH}}_{2}-\right), \quad 1.42-1.45$ (p, $\left.2 \mathrm{H},-\underline{\mathrm{CH}}_{2}-\mathrm{CH}_{2}-\mathrm{CH}_{2}-\mathrm{O}-\right), \quad 1.76-1.83\left(\mathrm{p}, 2 \mathrm{H},-\underline{\mathrm{CH}}_{2}-\mathrm{CH}_{2}-\mathrm{O}-\right), \quad 4.01-4.07$ $\left(\mathrm{t}, 2 \mathrm{H},-\mathrm{CH}_{2}-\mathrm{O}-\right), 7.41-8.30$ (d,1H, $\left.-\mathrm{CH}=\mathrm{CH}-\right), 7.59-7.62(\mathrm{~d}, 1 \mathrm{H},-\mathrm{CO}-\mathrm{C} \underline{\mathrm{H}}=\mathrm{CH}-), 7.82-7.86(\mathrm{~d}, 1 \mathrm{H},-$ $\mathrm{CO}-\mathrm{CH}=\mathrm{CH}-), 7.47-7.54 \& 8.08-8.11(4 \mathrm{H}$, middle phenyl ring), 6.91-6.93 \& 7.59-7.62 (4H, phenyl ring with alkoxy chain). The NMR data are reliable with the molecular structure.

IR in $\mathbf{~ c m}^{-1}$ for Heptyloxy Derivative

2997 (=C-H Str. of Phenyl nucleus), 2985 ( $\mathrm{CH}_{2}$ sym. \& asym. stra.), 1695 (Aromatic $\mathrm{C}=\mathrm{O}$ Str.), 1604 (aromatic C=C str.), 1516 (C-C aromatic str.), 1467 (C-H bend alkanes), 1336 (aromatic \& aliphatic C-O str.), 1124 (Ar-O str.), 844 (C-H oop. phenyl ring), 775 (C-H oop. bending of phenyl ring). The IR data are consistent with the molecular structure.

IR in $\mathrm{cm}^{-1}$ for Dodecyloxy Derivative

2995 (=C-H Str. of Phenyl nucleus), 2955 \& $2872\left(\mathrm{CH}_{2}\right.$ sym. \& asym. stra.), 1728 (Aromatic $\mathrm{C}=\mathrm{O}$ Str.), 1604 (aromatic $\mathrm{C}=\mathrm{C}$ str.), 1510 (C-C aromatic str.), 1467 (C-H bend alkanes), 1315 (aromatic\& aliphatic C-O str.), 1166 (Ar-O str.), 851 (C-H oop. phenyl ring), 777 (C-H oop.bending of phenyl ring). The IR data are consistent with the molecular structure.

Mass spectra of Butyloxy Derivative

$\mathrm{m} / \mathrm{z}$ (rel.int\%): $478(\mathrm{M})^{+}, 180,154,149,73$

Mass spectra of Octyloxy Derivative $\mathrm{m} / \mathrm{z}($ rel.int $\%): 534(\mathrm{M})^{+}, 388,325,249,208,129,113$ 


\section{RESULTS AND DISCUSSION}

$\alpha$-4-Hydroxy benzoyl- $\beta$-2'-bromophenyl ethylene is a nonmesomorphic component. However, on condensing it with 4-n-alkoxy benzoic acids, which are majorly mesomorphic, does it yield $\mathrm{C}_{1}$ to $\mathrm{C}_{7}$ nonmesomorphic and $\mathrm{C}_{8}$ to $\mathrm{C}_{16}$ homologues only smectogenic in nature without exhibition of nematic property. Transition temperatures of homologues (Table-2) were plotted against the number of carbon atoms present in n-alkyl chain of left n-alkoxy flexible terminal end group.

Table 2. Transition temperatures in ${ }^{\circ} \mathrm{C}$.

\begin{tabular}{ccccc}
\hline \multirow{2}{*}{$\begin{array}{c}\text { Compound } \\
\text { No. }\end{array}$} & $\begin{array}{c}\mathbf{R}=\mathbf{n} \text {-alkyl chain } \\
\mathbf{C}_{\mathbf{n}} \mathbf{H}_{\mathbf{2 n}+\mathbf{1}}\end{array}$ & \multicolumn{3}{c}{ Transition temperatures in ${ }^{\mathbf{0}} \mathbf{C}$} \\
\cline { 3 - 5 } & 1 & $\mathbf{S m}$ & $\mathbf{N}$ & Isotropic \\
\hline 1 & 2 & - & - & 147.7 \\
2 & 3 & - & - & 149.3 \\
3 & 4 & - & - & 166.5 \\
4 & 5 & - & - & 127.0 \\
5 & 6 & - & - & 160.9 \\
6 & 7 & - & - & 143.8 \\
7 & 8 & $(81.0)$ & - & 103.7 \\
8 & 10 & $(80.3)$ & - & 99.1 \\
9 & 12 & $(89.2)$ & - & 91.5 \\
10 & 14 & 88.6 & - & 98.4 \\
11 & 16 & 84.4 & - & 101.5 \\
12 & 16 & & - & 99.7 \\
\hline
\end{tabular}

Sm, Smectic; N, Nematic; ( ) indicate monotropy

Like or related points were linked to draw Cr-Sm or Cr-I and Sm-I transition curves as shown in a phase diagram showing (Figure-1) phase behaviors of a novel series. Cr-I or Cr-Sm transition curve adopt a zigzag path of rising and falling with overall descending tendency and behaved in normal manner. Sm-I or vice versa transition curve initially rises from $\mathrm{C}_{8}$ and passes through a maxima at the $\mathrm{C}_{14}$ homologue and then start to descend at $\mathrm{C}_{16}$ homologue, without exhibition of odd-even effect. Thus, both transitions curves behave in normal manner. 


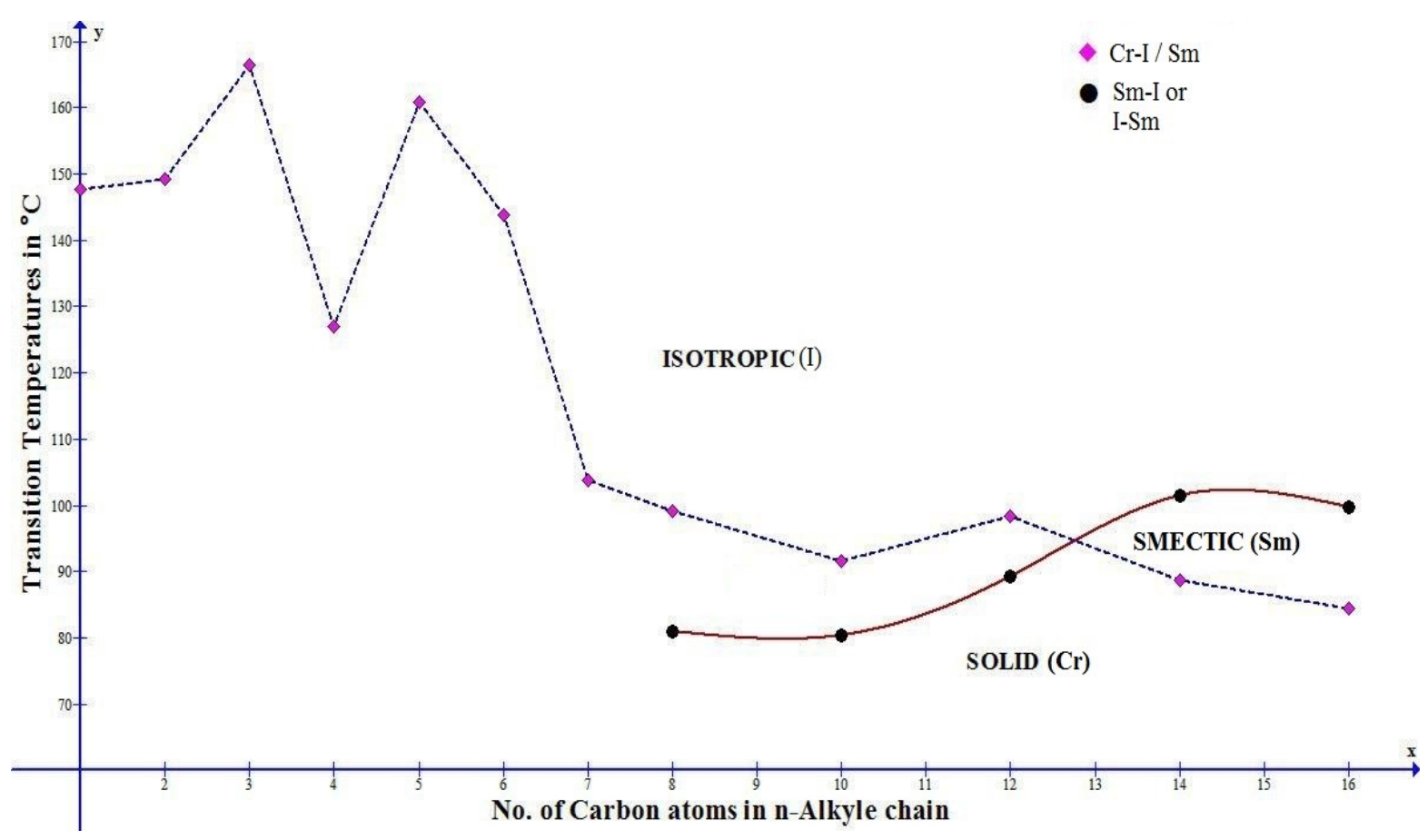

Figure 1. Phase Behavior of Series.

Textures of the smectic phase are focal conic fan shaped or batonates of the type smectic-A or smectic-C. Mesomorphic properties from homologue to homologue in present series undergo variations with changing molecular length, molecular polarity and polarizibility, etc. The mesogenic tendency of 4-n-alkoxy benzoic acid reduces on linking $\alpha$-4-hydroxy benzoyl- $\beta$-2'bromophenyl ethylene because, laterally substituted bromo functional group increases intermolecular distance which reduces intermolecular cohesion. Molecular polarizibility factor, though, can increase intermolecular attractions, but its contribution towards suitable magnitudes of anisotropic forces to induce mesomorphism is insufficient. Therefore, reduction in intermolecular attraction due to increased intermolecular width predominates between two opposing forces operating at a time for the same reason i.e. due to broadening of a molecule

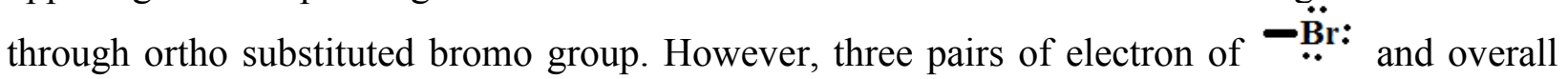
suitable magnitudes of anisotropic forces of intermolecular lateral attractions as a consequence of resultant molecular rigidity and flexibility as emerged from permanent dipole moment across the long molecular axis, dispersion forces and dipole-dipole interactions etc. are sufficient to maintain two dimensional molecular networking arrangement to form sliding layered arrangement of molecules in floating condition within definite temperature range. i.e. smectogenic mesophase formation facilitated to appear under microscopic observation from $\mathrm{C}_{8}$ to $\mathrm{C}_{16}$. The absence of nematic mesophase formation is attributed to the weaker end to end intermolecular attractions whose magnitudes are insufficient or below suitable magnitudes of anisotropic forces of intermolecular end to end attractions as required to maintain statistically parallel orientational order of molecule in floating condition. Therefore targeted homologues of present series $\left(\mathrm{C}_{1}\right.$ to $\left.\mathrm{C}_{16}\right)$ fails to resist exposed thermal vibrations and transform into isotropic liquid on heating under microscopic observations without exhibition of nematic mesophase formation either directly from crystalline state or through smectogenic LC state. The molecules 
are randomly oriented in all possible directions with high order of disorder or entropy $(\Delta \mathrm{S}=\Delta \mathrm{H} / \mathrm{T})$, under such situation. However, on cooling the same with suitable rate of cooling, the $\mathrm{C}_{8}, \mathrm{C}_{10}$ and $\mathrm{C}_{12}$ homologues exhibited monotropic mesophase formation and $\mathrm{C}_{1}$ to $\mathrm{C}_{7}$ homologues exhibited solid crystalline state without any monotropic mesophase formation. Non liquid crystallizing behaviors of $\mathrm{C}_{1}$ to $\mathrm{C}_{7}$ homologues is attributed to their high crystallizing tendency as a result of unsuitable magnitudes of manner rigidity and flexibility induced by low dipole-dipole interactions and low magnitudes of dispersion forces by the interactions between instantaneous dipoles produces by the spontaneous oscillations of the electron clouds of the molecules. Thus, liquid crystalline state exhibition is eliminated to appear under polarizing microscopy. The dimerization of 4-n-alkoxy benzoic acids disappears due to breaking of hydrogen bonding between to molecules by esterification process. The absence of odd-even and alternation of transition temperatures for Sm-I transition curve is attributed to the late commencement of LC phase from $\mathrm{C}_{8}$ homologue and onwards monotropically $\left(\mathrm{C}_{8}\right.$ to $\left.\mathrm{C}_{12}\right)$ and enantiotropically $\left(\mathrm{C}_{14}\right.$ to $\left.\mathrm{C}_{16}\right)$ which are of even membered. The longer n-alkyl chain of higher homologue $\left(\mathrm{C}_{8}\right.$ to $\left.\mathrm{C}_{16}\right)$ may be constrained to lie in the line with the major axis of the molecular core, the end to end or lateral contacts would then ultimately be the same for odd and even homologues and the alternation diminishes with increasing tendency of n-alkyl chain. The changing trend of mesomorphic behaviors from homologue to homologue in the same series is attributed to the sequential addition of methylene unit or units in the left n-alkoxy terminal end group keeping unchanged terminal group at the other end. Some LC properties of presently investigated novel series-1 are compared with structurally similar other known homologous series-X [21] and Y [22] as chosen for comparison as shown in figure-2.
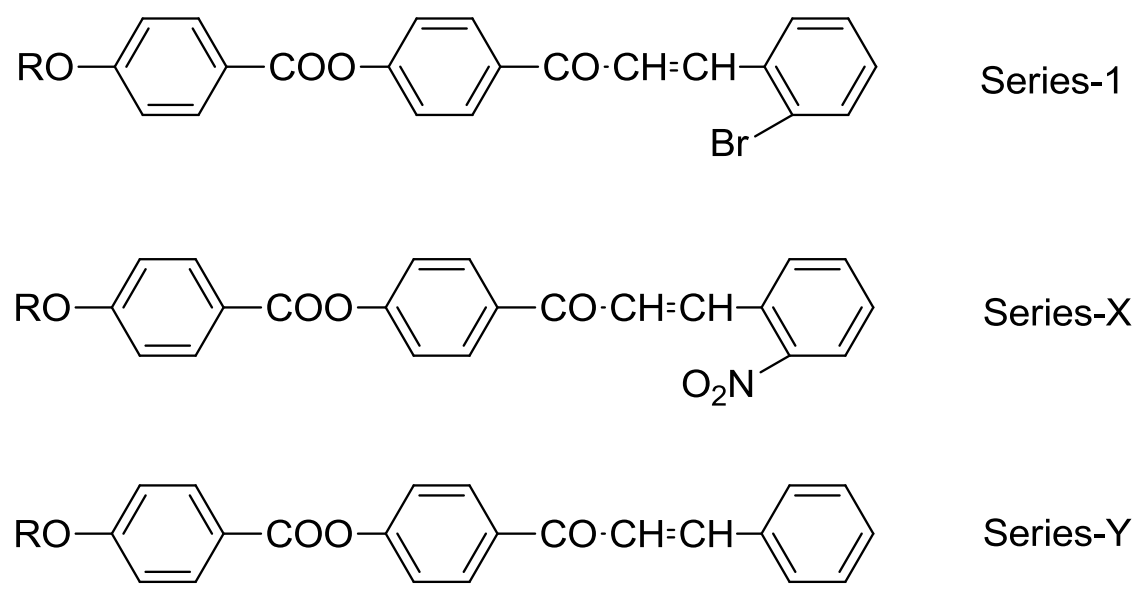

Figure 2. Structurally similar series.

Homologous series of present investigation and the homologous series-X and $\mathrm{Y}$ selected for comparison are identical with respect to three phenyl rings and two central bridges contributing to the total molecular rigidity and the number of carbon atoms present in n-alkyl chain present in left n-alkoxy terminal end group for the same homologue from series to series. But they differ with respect to laterally ortho substituted $-\mathrm{Br},-\mathrm{NO}_{2}$ and $-\mathrm{H}$ which contributes to the total molecular flexibility for the same homologue from series to series and from homologue to homologue in the same series. Therefore, the LC properties of series $1, \mathrm{X}$ and $\mathrm{Y}$ as well as their degree of mesomorphism can undergo variations of molecular flexibility for the same 
homologue from series to series and from homologue to homologue in the same series, keeping molecular rigidity unchanged. Table-3 represents some liquid crystal properties of series $1, \mathrm{X}$ and $\mathrm{Y}$ under comparative study.

Table 3. Average thermal stabilities in ${ }^{\circ} \mathrm{C}$.

\begin{tabular}{cccc}
\hline Series $\rightarrow$ & 1 & $\mathrm{X}$ & $\mathrm{Y}$ \\
\hline Smectic-Isotropic & 100.6 & 138.0 & - \\
$\left(\mathrm{C}_{14}-\mathrm{C}_{16}\right)$ & $\left(\mathrm{C}_{3}-\mathrm{C}_{14}\right)$ & - \\
$\begin{array}{c}\text { Commencement of smectic } \\
\text { mesophase }\end{array}$ & $\mathrm{C}_{8}$ & $\mathrm{C}_{3}$ & \\
Nematic-Isotropic & - & 163.7 & 164.5 \\
phase & $\left(\mathrm{C}_{3}-\mathrm{C}_{16}\right)$ & $\left(\mathrm{C}_{6}-\mathrm{C}_{8}\right)$ \\
$\begin{array}{c}\text { Commencement of nematic } \\
\text { potal Mesophase length } \\
\text { range (Sm+N) }\end{array}$ & $12.9\left(\mathrm{C}_{14}\right)$ & $\mathrm{C}_{3}$ & $\mathrm{C}_{6}$ \\
& to $15.3\left(\mathrm{C}_{16}\right)$ & $16.0\left(\mathrm{C}_{16}\right)$ & $7.0\left(\mathrm{C}_{16}\right)$ \\
to $49.0\left(\mathrm{C}_{10}\right)$ & to $45.0\left(\mathrm{C}_{10}\right)$ \\
\hline
\end{tabular}

From the table-3, it is clear that,

$\circ$ Homologous series 1 is only smectogenic and a series $\mathrm{Y}$ is only nematogenic; whereas series $\mathrm{X}$ is smectogenic plus nematogenic.

- Smectic thermal stability of series 1 is lower than series X. The smectic phase destabilized and absent for series Y.

- Nematic thermal stability of series $X$ and $Y$ are nearly equivalent $(163.7 \approx 164.5)$ but nematic mesophase does not stabilize even under monotropic condition.

- Smectic phase commences late from $\mathrm{C}_{8}$ member of a series 1 and it commences from $\mathrm{C}_{3}$ homologue for series $\mathrm{X}$ and it does not commence till the last $\mathrm{C}_{16}$ member of a series $\mathrm{Y}$.

$\circ$ Nematic mesophase commences from $\mathrm{C}_{3}$ and $\mathrm{C}_{6}$ homologues for series $\mathrm{X}$ and $\mathrm{Y}$ respectively; but it does not commence till the last $\mathrm{C}_{16}$ homologue of a series 1 .

- Total mesophase length is in the increasing order from series 1 to $\mathrm{X}$ to $\mathrm{Y}$.

The suitable magnitudes of anisotropic forces of end to end attractions facilitate nematic mesophase formation and the laterally substituted functional group forming two dimensional networking of sliding layered molecular arrangement due to lamellar packing of molecules in their crystal lattices favorably facilitate smectic mesophase formation in floating condition. Homologous series 1 and $\mathrm{X}$ do possess $-\mathrm{Br}$ and $-\mathrm{NO}_{2}$ as lateral groups respectively whereas series $\mathrm{Y}$ under comparison does have smallest lateral group - $\mathrm{H}$ or in general, it is laterally unsubstituted series. Therefore the molecules of series $\mathrm{Y}$ can be considered as linear path like molecules. Hence, the intermolecular closeness in case of series $\mathrm{Y}$ is the highest for series $\mathrm{Y}$ as compared to series $\mathrm{X}$ and 1. Laterally substituted $-\mathrm{Br}$ and $-\mathrm{NO}_{2}$ increases molecular width and decreases intermolecular anisotropic forces of end to end attractions which may be hinder to facilitate either statically parallel orientational order of molecules to eliminate nematic 
mesophase formation or may facilitate nematic mesophase formation of low degree of nematic mesophase length according to low intermolecular cohesion energy. But, on the other hand, laterally substituted functional groups $-\mathrm{Br}$ and $-\mathrm{NO}_{2}$ increases molecular polarizibility, which can raise suitable magnitudes of anisotropic forces of end to end and lateral intermolecular attractions relatively more than $-\mathrm{H}$. Thus, two opposing forces of intermolecular attractions are operated at a time for a same reason. However, the resultant net effect of intermolecular cohesion depends upon the predominancy of the effect operated at a time for the same reason. Triatomic $\mathrm{NO}_{2}$ group is more polar and polarizable than monoatomic $-\mathrm{Br}$ and $-\mathrm{H}$ functional group. Therefore, intermolecular cohesion due to predominancy of polarizability effect, including other intermolecular attractive forces undergo first smectic mesophase and then nematic mesophase formation is facilitated due to adequate suitable magnitudes of anisotropic lateral and end to end intermolecular forces which maintained, required sliding layered and parallel orientational order of molecules simultaneously in floating condition. Thus, series X exhibit smectic plus nematic phase. Presently investigated $-\mathrm{Br}$ substituted series 1 is relatively less polar and polarizable than series $\mathrm{X}$. Therefore, the first effect due to molecular widening or broadening shows their inability to maintain statistically parallel orientational order of molecules but, the intermolecular cohesion is sufficient to maintain only more ordered and the less thermally stable sliding layered arrangement of molecules in floating condition. The residual intermolecular cohesion forces after display of smectic phase has unsuitable magnitudes to cause nematic mesophase formation. Thus, only smectic mesophase formation takes place, excluding the exhibition of nematic phase in case of present series 1 . Series $\mathrm{Y}$ bearing weakest $-\mathrm{H}$ as lateral group whose polarity and polarizibility is zero or less than $-\mathrm{Br}$ and $-\mathrm{NO}_{2}$; maintains and predominates in end to end attractions only at the cost of smectic phase formation with facilitating the formation of only nematic phase of almost equivalent nematic thermal stability of series X. Thus, suitable or unsuitable magnitudes of anisotropic forces of intermolecular end to end or/and lateral attractions as a consequence of changing flexibility and keeping rigidity unchanged for the same homologue from series to series and from homologue to homologue in the same series, which depend upon molecular structure, causing disalignment of molecules at an angle less than ninety or perpendicular to the plane of a floating surface generating resistivity against exposed thermal vibrations in different proportions as related to varying polarity and polarizibility of tail end groups affecting the commencement of smectic and/or nematic phase early or late due to the differing extent of molecular noncoplanarity; different, transition temperatures, mesophase length, thermal stabilities for smectic and nematic phase etc and other LC properties.

\section{CONCLUSIONS}

$\circ$ Ortho substituted $-\mathrm{Br}$ group of novel series is smectogenic from $\mathrm{C}_{8}$ to $\mathrm{C}_{16}$. Homologues $\mathrm{C}_{1}$ to $\mathrm{C}_{7}$ are nonliquid crystal.

oGroup efficiency order derived for smectic and nematic on the basis of (i) Thermal stability (ii) commencement of mesophase (iii) Total $(\mathrm{Sm}+\mathrm{N})$ mesophase length range are as under.

$$
\begin{aligned}
\text { Smectic: }-\mathrm{NO}_{2}>-\mathrm{Br}>-\mathrm{H} \\
\text { Nematic: }-\mathrm{NO}_{2} \approx-\mathrm{H}>-\mathrm{Br} \\
\text { Smectic: }-\mathrm{NO}_{2}>-\mathrm{Br}>-\mathrm{H} \\
\text { Nematic: }-\mathrm{NO}_{2}>-\mathrm{H}>-\mathrm{Br}
\end{aligned}
$$


(iii) $\mathrm{Sm}+\mathrm{N}:-\mathrm{H}>-\mathrm{NO}_{2}>-\mathrm{Br}$

oSuitable magnitudes of anisotropic forces of intermolecular end to end or/and lateral attractions as a consequence of molecular rigidity and/or flexibility are operating liquid crystal behaviors.

oMesomorphism of a substance is very sensitive and susceptible to its molecular structure.

oNovel substances of present series may be useful to the study of binary system which may operate LC devices at about $60^{\circ} \mathrm{C}$ to $65^{\circ} \mathrm{C}$ and their biological activity for pharmaceutical preparations.

\section{Acknowledgement}

Authors acknowledge thanks to the Department of Chemistry (DST-FIST Funded \& UGC-SAP Sponsored), Saurashtra University, Rajkot, for research work. Authors are also thankful to Dr. A.V. Doshi, Ex. Principal M.V.M. Science and Home Science College Rajkot, for his valuable co-operation during present investigation as and when needed. Also thanks to the National Facility for Drug Discovery through New Chemical Entities (NCE's) for analysis of samples.

\section{References}

[1] Reinitzer, F., Monatsh (1888). 9, 421.

[2] Naemura, S. (2001). Advance LCD technologies, Displays, 22 (1), 1.

[3] Kim,W.S., Elston, S.J., \& Raynes, F.P. (2008). Display, 29, 458-463.

[4] Talwa, I., Dr.Salnana Shahi, Ramteke,V., \& Syed, I., (2012). "Liquid crystal Pharmaceutical Application: A Review", “IJPRAS” International journal of Pharmaceutical Research and Allied Science, 1(2), 06-11.

[5] Lee, Y.S., Lim, S.S., Shin, K.H., Kim, Y.S., Ohuchi, K. \& Jung, S.H. (2006). Bio.Pharm.Bull, 29, 1028-1031.

[6] Imrie, C.T. (1999). Liquid crystal dimers, Structure, Bond, 95,149-192.

[7] Gray, G. W., \& Windsor, P.A. (1974). Liq. Cryst. Plastic Cryst., Ellis Horwood: Chichester, U.K., 1 (4), 103-153.

[8] Gray, G. W. (1962). Molecular Structure and the Properties of Liquid Crystal., Academic Press: London.

[9] Demls, D. (1988). 100 years of Liquid Crystal Chemistry, Mol. Cryst. Liq. Cry., 165, 45-84.

[10] Demus, D. (1989). Plenary lectures 100 years of Liquid Crystal Chemistry, Thermotropic liquid crystals with conventional and unconventional molecular structure, Liq. Cry., 5, 75110.

[11] Imrie, C.T. \& Luckhrust, G.R. (1998). Liquid Crystal dimers and oligomers: Handbook of liquid crystal, law molecular liquid crystals, 2B, Demus,D., Goodly, J.W., Spiess, H.W. and Vill,V.,willey-VCH, weinhei, 801-833. 
[12] (i) Suthar, D.M., \& Doshi, A.V., (2013). Mol.Cryst. Liq.Cryst., 575, 76-83. (ii) Chuhan, H. N., \& Doshi, A. V. (2013). Mol. Cryst. Liq. Cry., 570(1), 92-110. (iii) Chaudhari, R. P.,Chauhan, M.L. \& Doshi, A.V., (2013). Mol. Cryst. Liq. Cryst., 575, 88-95. (iv) Bhoya, U. C., Vyas, N. N., \& Doshi, A. V. (2012). Mol. Cryst. Liq. Cryst., 552, 104-110.

[13] Gray, G.W. \& Jones, B. (1954). "The effect of halogen substitution on the 4-alkoxy benzoic acid", Mesomorphism and chemical constitution part-III, J. of Chem. Soc., 2556-2562.

[14] Hird, M., Toyne, K. J., Gray, G. W., Day, S. E., \& Mc Donnell, D. G. (1993). Liq. Cryst., $15,123$.

[15] Collings, P.J., \& Hird, M. (1998). "Introduction to liquid crystals chemistry and physics", Taylor and Fransis Ltd, U.K.

[16] Marcos, M., Omenat, A., Serrano, J. L. \& Ezcurra, A. (1992). Adv. Mater., 4, 285.

[17] Hird, M., Toyne, K. J., \& Gray, G. W. (1993). Liq. Cryst., 14, 741.

[18] Dave, J. S., \& Vora, R. A., (1970). Liquid Crystal and Ordered Fluids, Plenum Press: New York, Graw, G. W. (1958). Steric effect in conjugated systems. Ed., Butterworths, London, 477.

[19] Dave, J. S., \& Vora, R. A., (1970). In: J.F. Johnson and R.S. Porter, (Eds), Liquid Crystal and Ordered Fluids, Plenum Press: New York, 477.

[20] Nagaveni, N.G., \& Prasad, V., (2013). “Azo substituted V-shaped liquid crystalline compounds: synthesis and mesophase characterization", Phase Tran. 86, 12, 1227-1240.

[21] Chauhan, H. N., Vyas,N. N., \& Doshi, A. V., (2013) Mol. Cryst. Liq. Cryst., 575, 96-103.

[22] Chauhan, M. L., \& Doshi, A. V. (2007). J. Ind. Chem. Soc., 84, 774-776. 